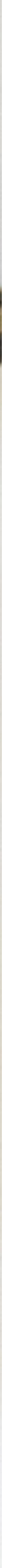




\section{El llavero, coleccionando memorias}

Cecilia León de la Barra

En esta investigación se busca reconocer los valores asociados con el uso normativo del llavero y sus posibles variantes en la práctica social. Los resultados apuntan a los atributos simbólicos de este objeto, los cuales no parecen estar relacionados con su función aparente (identificar y agrupar llaves), sino con la identificación y la recolección de recuerdos.

Palabras Clave: llavero, uso normativo, símbolo, llaves 

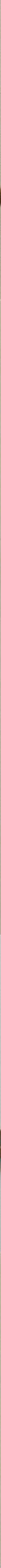
El llavero es un objeto de uso corriente. Como su nombre lo denomina, sirve para colocar e identificar las llaves, por lo que se usa con frecuencia. Suele estar compuesto por una argolla metálica en la cual se colocan las llaves, a la cual se añaden ornamentos formas y materiales diversos; justo esta amplia variedad permite que su diseño tienda a ser personal.

El aro metálico para portar las llaves fue inventado en Rusia alrededor de 1830; en 1922 Herluf Johnson patentó el aro en espiral en los Estados Unidos y para 1970 se mejoró el diseño, facilitando el acto de meter y sacar las llaves, así como agregar algún accesorio o adorno. Como objeto de diseño, la historia del llavero se relaciona con la de la llave. Alice Rawsthorn (2013) afirma que durante cientos de años las llaves fueron objetos muy bellos, hechos a mano por hábiles artesanos y forjados en metales preciosos; en la era industrial las llaves se volvieron más delgadas, más pequeñas, uniformes y en esta medida, ordinarias.

La llave expresa el valor de la posesión: está asociada con una cerradura, que a su vez está en una puerta que custodia algo. Una habitación, un tesoro, un secreto. En un primer momento podríamos afirmar que el valor del llavero está vinculado al de la llave que porta, si bien el presente estudio arrojó un valor autónomo de este objeto.

Para explorar la relación del objeto en términos de utilidad o utensilio descrita por Martín Juez (2002), se conformó una colección de imágenes de llaveros pertenecientes a diferentes personas, a las que se les pidió mostrar sus llaveros, mismos que portaban en el bolsillo, el bolso, la mochila, el cajón o el portallaves de pared, según el caso. Este ejercicio reveló la posesión de más de un llavero asociado con el lugar o el objeto en cuestión (casa, trabajo, auto, etc.) y todos ellos fueron debidamente registrados (véase figura 1).

Posteriormente, se realizó una colección de imágenes de diferentes fuentes, en su mayoría páginas de internet. La recuperación del material se realizó del 2 febrero al 20 de mayo de 2013 y arrojó un total de 353 imágenes de llaveros de distintas épocas y culturas, cuya tipología preliminar resultó ser la que se presenta en la figura 2. Esta exploración arrojó un primer resultado de interés, además de la tipología antes señalada. Los llaveros se asocian con la práctica del coleccionismo y cuando forman parte de una colección, estos objetos no se utilizan para portar llaves.

\section{Marco conceptual}

Consideremos al llavero como un souvenir típico y recordemos lo que dice Marcel Mauss (2007) cuando refiere a los dones intercambiados y a la obligación de devolverlos:
(...) en el derecho maorí, el vínculo de derecho, vínculo por las cosas, es un vínculo de almas, pues la cosa misma tiene un alma, es alma.

De lo que se deriva que regalarle algo a alguien es regalar una parte de uno mismo. También, así nos damos cuenta mejor de la naturaleza misma del intercambio por dones, de todo aquello que llamamos prestaciones totales y, entre éstas, la del "potlach". Se comprende clara y lógicamente que, en ese sistema de ideas, haya que devolver al otro lo que en realidad forma parte de su naturaleza y su sustancia; pues aceptar algo de alguien es aceptar algo de su esencia espiritual, de su alma (p. 90).

En este tenor, se observa que coleccionar, y coleccionar llaveros en específico es todo un fenómeno en el mundo. Siguiendo a Baudrillard (1969):

\begin{abstract}
Así, pues, el coleccionista no es sublime por la naturaleza de los objetos que colecciona (éstos varían según la edad, la profesión, el medio social), sino por su fanatismo. Fanatismo idéntico en el rico aficionado a las miniaturas persas y en el coleccionista de cajas de cerillos. Por esto la distinción que se pretende realizar entre el amateur y el coleccionista, el último de los cuales amaría los objetos en función de su sucesión en una serie, en tanto que el primero lo haría por su encanto diverso y singular, no es decisiva. El goce, de uno y otro, proviene de lo que la posesión juega, por una parte, sobre la singularidad absoluta de cada elemento, que lo hace equivalente de un ser, y en el fondo del sujeto mismo, y por otra parte expresa la posibilidad de la serie, por consiguiente, de la sustitución indefinida y del juego (p. 100).
\end{abstract}

Una colección, según la Real Academia Española, es un conjunto ordenado de cosas de una misma clase y reunidas por su especial interés o valor. La Bruyère en 1688 refiere a la colección y el impulso de coleccionar en Francia:

Coleccionar no es un gusto de lo que es bonito o bueno, es de lo que es excepcional y único, de lo que uno tiene y los demás no. No es un apego de lo que es perfecto, pero de aquello que es buscado y está de moda. No es un entretenimiento, es una pasión a veces tan violenta que no es menos potente que el amor o la ambición, excepto por la pequeñez del objeto. No es una pasión que uno tiene por cosas con valor excepcional, sólo por cierta cosa que es excepcional y que al mismo tiempo está en boga (La Bruyère en Chang, 1996, p. 95).

Las colecciones empiezan con la acumulación o repetición de objetos, en este caso de los llaveros. Cabe aclarar que acumular 
no es exactamente coleccionar. Un coleccionista es ordenado, cuidadoso, le gusta enseñar, incluso hasta presumir su colección, acumular puede ser algo desorganizado, fragmentado, sin un tema claro o sentido para esta recopilación de objetos. Para mí, esto puede formar parte de una especie de psicopatología que está muy cercana a la de los hoarders o acaparadores de objetos. "La mayoría de los objetos reflejan únicamente la dimensión del yo personal, si se usan exclusivamente para expresar la individualidad de cada uno, podemos asumir entonces la existencia de una patología básica" (Csikszentmihalyi \& Rochberg-Halton, 1981, p. 40).

Por su parte Susan Pierce (1995) identifica tres tipos de colecciones. El souvenir, una colección intensamente personal o "curiosa", reunida por un individuo a lo largo de su vida, tiene una memoria y está asociada a la producción, la acumulación, la compra o el uso; la sistemática: con una aproximación académica a la manera de coleccionar, en que los objetos representan principios de organización científicamente verificados por medio de la observación y el estudio; la fetichista, que consiste en objetos que son "ingeniosos" o "curiosos", coleccionados por personas cuya imaginación se identifica con las cosas que desean reunir.

Lo que unifica a estas tres categorías es la creencia compartida de que dichos objetos son una expresión de su dueño. La analogía de la colección como espejo es muy buena, no porque refleja imágenes reales, sino que refleja las imágenes deseadas. Somos lo que tenemos y usamos.

La naturaleza de coleccionar está fundamentada en elecciones individuales. Qué categoría de cosas a coleccionar es una opción clave, en qué piezas enfocarse es otra. Infaliblemente, estas decisiones revelan la personalidad detrás de la colección. En el caso de los llaveros, sus colecciones podrían considerarse poco valiosas, pues muchos de los llaveros caen dentro de la categoría de las chucherías o baratijas. Aquí lo importante para el coleccionista son las historias y el origen de cada pieza. No tanto el precio, ni la edición, ni el material del objeto.

Para entender más las colecciones, habría que explorar de fondo al objeto. Barthes trata de definir al objeto antes de ver qué puede significar, "Comúnmente definimos al objeto como 'una cosa que sirve para alguna cosa'. El objeto es por consiguiente, a primera vista, absorbido en una finalidad de uso, lo que se llama una función" (Barthes, 1993, p. 246). Si pensamos que el llavero es una cosa, "las cosas son también útiles o utensilios (...) un utensilio es un objeto que sirve para el uso frecuente, y que un objeto sea útil es su principal atractivo" (Juez, 2002, p. 33). En el caso del llavero, a veces el principal atractivo no es lo útil, sino de dónde viene, cómo es o quién lo regala. "todo objeto tiene dos funciones: una la de ser utilizado y la otra la de ser poseído(...) Estas dos funciones están en razón inversa la una de la otro" (Baudrillard, 1969, p. 98).

Por ejemplo, si pensamos en el llavero como souvenir, como un recuerdo de algún viaje o visita a un lugar, se vuelve un objeto con una carga simbólica, llena de recuerdos e historias. "Lo que aquí importa es la historia de la interacción, las asociaciones que establecemos con los objetos y los recuerdos que éstos evocan en nosotros" (Norman, 2005 p.62). El llavero con la figura de la Torre Eiffel, que alguien trajo de su visita a París, o el llavero con conchas y arena encapsuladas en resina que dicen: Recuerdo de Ixtapa. "Un souvenir está fabricado para que sirva como un recuerdo (la palabra en francés, quiere decir: memoria) de una experiencia poco ordinaria, de un lugar o una cultura" (Boym, 2002, p. 71).

Si los llaveros, además de acompañar a diario y abrir y cerrar lugares y/o cosas, son objetos que están llenos de historias o recuerdos, son estas historias y recuerdos que su dueño nos cuenta las que hablan de la personalidad del objeto y del usuario. En este sentido, Csikzentmihalyi y Rochberg-Halton (1981) afirman:

Los objetos con los cuales la gente se rodea y usa, podrían reflejar de manera muy precisa la personalidad su dueño... todos son expresiones de uno mismo, aun cuando actúan como disfraces en vez de reflejos. Es más difícil admitir que las cosas que uno usa son en realidad parte de uno mismo (p. 14-15).

Entonces, llenarnos de objetos con historias y recuerdos, nos puede llevar a acumularlos o a coleccionarlos al no querer desprendernos de ellos. Tenemos un apego por estos objetos materiales por su significado e historia, eso hace que los guardemos y los convirtamos en una colección.

Para poder entender qué significa el llavero dentro de un contexto específico, es importante además de la observación, hacer preguntas, ¿de dónde viene, cuántas partes tiene, cómo está hecho, de qué materiales, dónde y cómo se usa y cuál es su lugar dentro de la casa? Tal como lo dice Pearce (1994):

(...) debemos de poder hacer preguntas cómo, qué, dónde, cuándo, por quién y para qué de cualquier objeto o artefacto para poder obtener respuestas interesantes. Propone una manera sustancial para organizar al estudio de un objeto, dividirlo en cuatro áreas generales: por materiales, (la materia prima, el diseño y la tecnología); la historia, (una descripción de su funcionamiento y su uso); el entorno, (relaciones espa- 


\section{Llavero}

\section{FORMA}

espiral gancho

\section{TEMAS}

- amuleto

- imágenes religiosas

- juguetes

- figuras personajes comerciales

- marcos promocionales

- logotipos

- como tarjetas de presentación

- recuerdo de eventos

- temas marinos

- animales

- hípicos

- letras

- nombres completos

- apellidos

- lugares

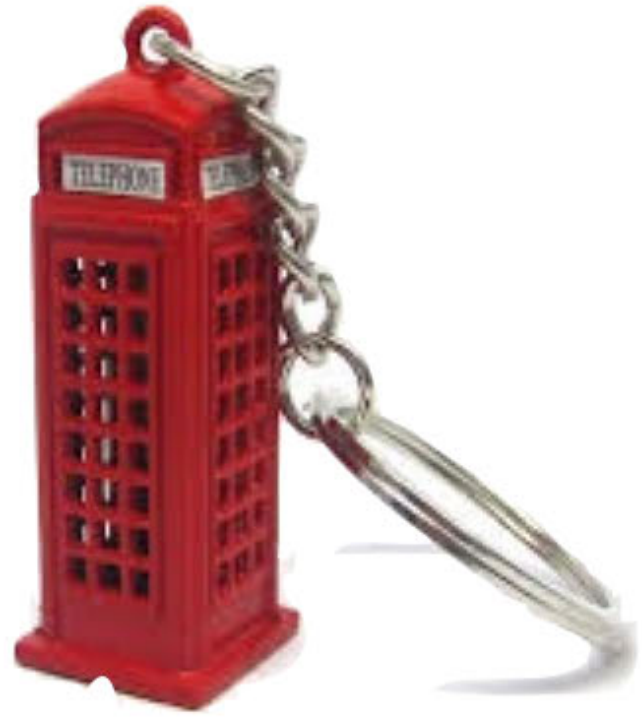


ciales) y significado (adopta los mensajes emocionales y psicológicos). La suma del entendimiento de estas propiedades se podría describir como interpretación (p. 126).

Para entender a cualquier objeto, primero es fundamental la observación. El análisis comienza a partir de las historias que uno asume que cuentan los objetos. De esta manera se logra una interpretación de su uso, para después reinterpretar al mismo dentro de cualquier contexto cultural específico.

Tal como afirma Clifford Geertz (2005), la antropología interpretativa busca darnos acceso a respuestas encontradas por otros, no sólo a nuestras preguntas. Si queremos saber qué significa el Ilavero, o su biografía, debemos contestar la mayor parte de estas preguntas, tratar de descifrar qué significa para su dueño, ¿cómo lo usa, cómo llegó a su vida, dónde lo guarda y qué significa ese objeto para esa persona? Y así hacer nuestras interpretaciones. "lo que nosotros llamamos nuestros datos son realmente interpretaciones de interpretaciones de otras personas sobre lo que ellas y sus compatriotas piensan y sienten" (Geertz, 2005, p.23). Esta mirada nos permitirá generar la información necesaria para una ulterior problematización en torno al objeto.

Si tratamos de estudiar la biografía del llavero, podemos llegar a descubrir mucha información del objeto así como de su dueño. De acuerdo con Gosden y Marshall (1999):

(...) la biografía de los objetos se remonta a Kopytoff (1986) quién sentía que las cosas no podían ser entendidas en su totalidad en un punto de su existencia y sus procesos así como sus ciclos de producción, el intercambio y el consumo tenían que ser vistos como un todo... No sólo los objetos cambian durante su existencia, muchas veces tienen la capacidad de acumular historias, para que el significado de algún objeto derive de las personas y los eventos a los que está conectado (...) (p.170)

El llavero es muy común como regalo, es práctico, de buen tamaño, se vuelve un detalle. Si lo contemplamos como un souvenir, es un objeto barato que preserva la memoria del viaje y es portador simbólico del momento en el que el viajero recordó a la persona que le inspira afecto. En este tenor, el souvenir contribuye a preservar la memoria.

\section{Metodología}

Para explorar el valor del llavero en sí mismo se siguieron los lineamientos que Susan Pearce describe en su texto Thinking about Things (1994):
Una manera efectiva para organizar las propiedades de un objeto con el propósito de estudiar al artefacto en cuestión, es dividir el estudio en cuatro áreas: material, que incluye a la materia prima, el diseño, el ensamblaje y la tecnología; historia, que describe su función y uso; entorno, que involucra todas las relaciones del artefacto con el espacio; y significado, que arropa todos los mensajes emocionales y psicológicos. La suma del entendimiento de estas propiedades puede describirse como interpretación (p.126).

Partiendo de lo antes mencionado, la metodología para el estudio del llavero consistió en un exhaustivo registro fotográfico de varios ejemplos durante cuatro meses. En su mayoría, el registro fotográfico se hizo en la Ciudad de México, y algunas visitas esporádicas a Guadalajara y Chihuahua. Llegué a fotografiar más de 300 llaveros de gente que conocía, así reuní cerca de 250 casos (figura 1); el resto de las imágenes fueron enviadas por amigos o conocidos. También documenté algunos de los lugares donde se guardan, venden o exhiben los llaveros (tiendas departamentales, tiendas de aeropuertos, puestos de mercados, papelerías).

La observación de los casos me permitió identificar recurrencias; observé primero dos grandes grupos; los llaveros con llaves y los llaveros sin llaves. La otra categoría importante fue la de los Ilaveros de las llaves del coche y los de la casa. Entonces, empecé a desagregar los grupos; los llaveros promocionales o de marca, los llaveros amuletos o religiosos, los llaveros con personajes o juguetes, los llaveros con temas marinos o hípicos y los llaveros con otra función (lámpara, desarmador, destapador, memorias USB). Estas categorías siguen a Susan Pearce y atendieron a preguntas relativas a la forma y el material, ¿cómo son, qué forma tienen, si tienen llaves o que otra cosa portan? Después los ubiqué por su manufactura, ¿cómo estaban hechos, cómo funcionan, cómo se guarda la llave (con argollas de metal en espiral, con ganchos, con rosca para un tornillo, con un clip), y si tienen más de una argolla o gancho? Así, seguí clasificando y categorizando hasta percatarme de que en muchas ocasiones el dueño siempre tenía más de un llavero guardado sin llaves, y que por lo general entraban en la categoría del souvenir. Eran llaveros que alguien les había regalado, o que habían comprado en algún viaje ya sea para ellos o para después dar como regalo. Lo interesante fue que cada uno tenía sus llaveros en una misma línea o un tema, es decir, marinos o náuticos, los "curiosos" de playa como los de resina con conchas y arena, o los llaveros de mundiales y olimpiadas.

Seleccioné a tres usuarios cercanos a mí que tuvieran al menos más de treinta llaveros; los tres son varones, de 29, 38 y 68 años, respectivamente. Dos diseñadores industriales y un administrador. 
El fenómeno del souvenir está muy excluido de la cultura del diseño e ignorada por completo por las profesiones del diseño. Si aceptamos que diseñar es una manera de comunicar ideas, entonces los souvenirs son los objetos de diseño por excelencia. Pueden portar capas muy complejas de información, desde mensajes "programados" hasta sentimientos personales (...) Por lo tanto, los souvenirs, tienen el potencial de ser transformados de productos superfluos de consumo en objetos de supervivencia emocional. En vez de un cliché de turista, un souvenir puede servir como una digna representación de la cultura e identidad de una persona (p. 70).

Esta asignatura pendiente señala un área de oportunidad para los diseñadores, cuyo trabajo creativo puede contribuir a llevar a nuevos caminos la función del llavero como ancla de la memoria.

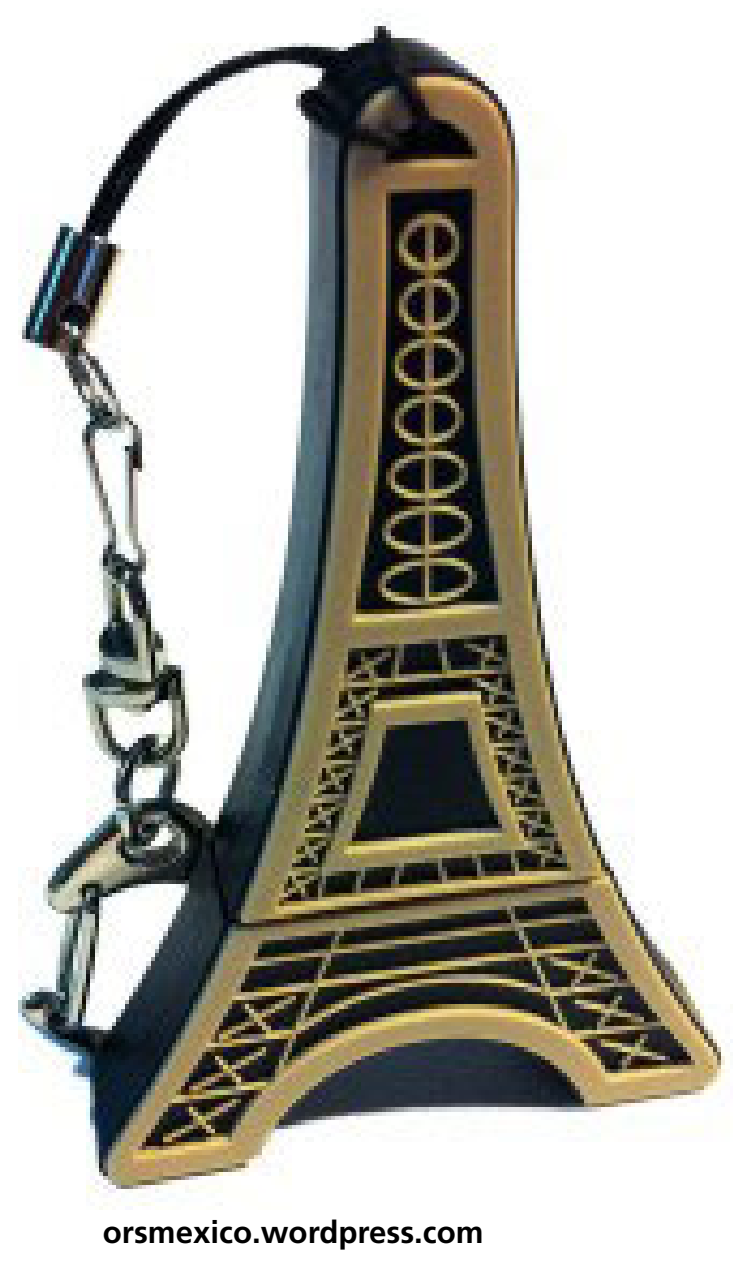




\section{Referencias}

Aneez, Z. (2013, 4 de abril) Key 'chains' to happiness. The Hindu. Recuperado el 12/04/2013 de http://www.thehindu. com/todays-paper/tp-features/tp-metroplus/key-notes/article4628378.ece

Barthes, R. (1993). La Aventura Semiológica.

Barcelona: Paidós Comunicación.

Baudrillard, J. (1969). El Sistema de los Objetos.

México: Siglo XXI.

Boym, C. (2002). Curious Boym: Design Works. Nueva York: Princeton Architectural Press.

Chang, T. (1996). Models of Collecting. Oxford Art Journal, Vol. 19, No. 2 pp. 95-97.

Recuperado el 03/05/2013 de http://www.jstor.org/discover/10.2307/1360732? uid=3738664\&uid=2\&uid=4\&sid $=21103245220421$.

Csikszentmihalyi, M. y Rochberg-Halton, E. (1981).

The meaning of things. Domestic symbols and the self, Reino Unido: Cambridge University Press.

Geertz, C. (2005). La interpretación de las culturas. Barcelona: Gedisa.

Gosden, C. y Marshall, Y. (1999). The Cultural Biography of Objects. World Archaeology, Vol. 31, no. 2,

pp. 169-178. Recuperado el 03/05/2013 de http://www.jstor. org/discover $/ 10.2307 / 125055$ ? uid=3738664\&uid=2\&uid=4\&sid $=21103245220421$.

Guinnes World Records. (n.d) Recuperado el 22/04/2013 http://www.guinnessworldrecords.com/ world-records/1/ largest-collection-of-keychains.
Libby Sellers. (2010). Why What How Collecting Design in a Contemporary Market. Reino Unido: HSBC Private Bank.

Martín Juez, F. (2002). Contribuciones para una antropología del diseño. Barcelona: Gedisa.

Mauss, M. (2007). Ensayo sobre el don. Forma y función del intercambio en las sociedades arcaicas. Buenos Aires: Katz Editores. Trabajo original publicado en 1925.

Norman, D. (2005). Diseño emocional. Por qué nos gustan (o no) los objetos cotidianos. Barcelona: Paidós.

Pearce, S. (1994) Interpreting Objects and Collections. Nueva York: Routledge.

(1995) On Collecting: An Investigation Into Collecting In The European Tradition. Nueva York: Routledge.

Phaidon Design Classics. (2006). (Vol.3). China: Phaidon Press Inc. p. 667-999.

Rawsthorne, A. (2013, 3 de marzo) You Can't Open a Lock Without One, The New York Times. Recuperado el 03/03/2013http://www.nytimes.com/2013/03/04/arts/design/ you-cant-open-a-lock-without-one.html?_r=0

The Collector (2011). Vol. 3, no. 4 (Dec.15, 1891) pp.56-57. The Souvenir Spoon Craze. Recuperado el 20/04/2013 de http://www.jstor.org/stable/25601778.

The Souvenir Spoon Craze. (2011). The Collector, Vol. 3 (No. 4), pp. 56-57. Recuperado el 20/04/2013 de http://www.jstor.org/ stable/25601778 Trabajo original publicado en diciembre 15 de 1891. 